\title{
Assessing the Consequences of the Pandemic for the Russian Economy Through an Input-Output Model
}

\author{
Aleksey Ponomarenko, Bank of Russia \\ ponomarenkoaa@mail.cbr.ru \\ Svetlana Popova, Bank of Russia \\ popovasv@mail.cbr.ru \\ Andrey Sinyakov, Bank of Russia \\ sinyakovaa@mail.cbr.ru \\ Natalia Turdyeva, Bank of Russia \\ turdyevana@mail.cbr.ru \\ Dmitry Chernyadyev, Bank of Russia \\ chernyadevdn@cbr.ru
}

This paper evaluates the impact of anti-coronavirus measures on the dynamics of economic activity. In addition to primary shocks directly caused by restrictive measures, we assess their secondary effects through inter-industry relationships. Our assessments show that secondary effects impact more industries than primary effects do. The overall impact of secondary effects on the economy proves to be of a larger scale than the impact of primary effects with high heterogeneity of dynamics by industry.

Keywords: COVID-19, input-output model, payment system, GDP

JEL Codes: C53, C67, I1
Citation: Ponomarenko, A., Popova, S., Sinyakov, A., Turdyeva, N. and Chernyadyev, D. (2020). Assessing the Consequences of the Pandemic for the Russian Economy Through an Input-Output Model. Russian Journal of Money and Finance, 79(4), pp. 3-17. doi: $10.31477 /$ rjmf.202004.03

\section{Introduction}

The economic shock the global economy confronted in 2020 due to the spread of the coronavirus pandemic is unique and strikingly different from previous global economic recessions. This year, the main reason for the decline in economic activity is the introduction of restrictive measures in various countries, designed to slow the spread of the pandemic and reduce the burden on the healthcare system.

For the economy, the impact of anti-coronavirus measures is both a demand shock and a supply shock. Both reduce the volume of goods and services produced in the economy. The more the operations of companies and enterprises and the 
intra-regional and inter-regional mobility of the population are restricted, the more noticeable the impact of these restrictions on economic activity is. The immediate impact of restrictive measures is a primary shock to the economy. In addition, primary shocks include a decrease in external demand for Russian goods and services due to the decline in the global economy, which, in turn, is caused by the effect of restrictive measures and their consequences for the economies of various countries. Our study aimed to assess the scale of the recession in the Russian economy caused by both primary shocks directly linked to restrictive measures and secondary effects they create.

One way to assess secondary effects on the economy is to estimate the propagation of shocks through inter-industry relationships. An input-output model (or input-output table) makes it possible to calculate how a decrease in final demand in one industry, through a proportional decrease in its demand (intermediate consumption), may affect the dynamics of production in other industries, which, for example, were not initially subject to restrictive measures or other shocks.

We model two types of primary shocks: external and internal. External shocks manifest themselves through a decrease in exports of key commodities (oil, petroleum products, metals, machinery and equipment). The introduction of restrictive measures in different countries has already led to a sharp reduction in world trade and a decrease in external demand for Russian export products. Internal shocks manifest themselves through deviations in the dynamics of final household consumption. We did not specify the dynamics of primary shocks in the intermediate consumption of goods and services since one of the objectives of the analysis was to assess the impact of primary consumption shocks (internal and external) on the dynamics of value added in other industries through the intermediate consumption of their products.

Our calculations are dynamic. We assume various speed of response of companies' costs to intermediate consumption, which is consistent with how companies operate in reality. At the moment of a sharp decline in demand, they may not immediately react with a decrease in production but accumulate product stocks for some time and only thereafter adjust production plans.

For primary shocks, we determined a weekly trajectory of deviation from the normal (pre-coronavirus) level. Estimates for the deviation of internal shocks for the first weeks were taken as the average deviation of financial inflows from the normal April figures in the respective industries. For the dynamics of external shocks, we took into account the estimates of the decrease in external demand for Russian goods through inter-industry ties with other countries during the global recession based on the forecast of the International Monetary Fund (IMF) published in June 2020 (see International Monetary Fund, 2020).

Hereinafter, we proceeded as follows. Section 2 provides an overview of studies evaluating the impact of the coronavirus pandemic and the impact of restrictive measures. In Section 3, we define and describe the input-output model of the 
Russian economy that was used for the calculations. In Section 4, we introduce the definition of primary shocks and describe a mechanism for determining weekly trajectories for both internal and external shocks used for the calculations. In Section 5, we obtain estimates of the impact of primary and secondary effects on the dynamics of economic activity and draw several important conclusions regarding the relationship between their dynamics, sustainability, and economic policy measures aimed at accelerating economic recovery and mitigating the impact of secondary effects. Section 6 presents the conclusion.

\section{Literature review}

The start of the global coronavirus pandemic motivated many studies aimed at assessing the consequences of both the pandemic and the restrictive measures (quarantine, social distancing) on economies worldwide. ${ }^{1}$ Our paper is one such study. It has the following specific characteristics.

1. A key role in our calculations is played by the industry structure of demand and production shown in the input-output tables, which determines the character of the shock transmission. ${ }^{2}$ The strong heterogeneity of the industry-level primary effects of the pandemic raises the question of the role of individual industries in the aggregate effect at the macroeconomic level. Using data from input-output tables or more granular data for the Japan, UK, France, and other European economies, Pichler et al. (2020), Inoue and Todo (2020), and Barrot et al. (2020) show that industries that play an important role in the structure of GDP may not experience the direct effects of the pandemic and social restrictions. At the same time, such industries may be under pressure from industries affected by the primary shock of the pandemic on the supply or demand side. ${ }^{3}$ Underestimation of such effects in macroeconomic models used to predict the impact of the pandemic may lead to an inaccurate assessment of the situation and errors in government and central bank policies.

Calculations are often based on computable general equilibrium models, as in Barrot et al. (2020). In such models, changes in relative prices ensure the adjustment of the economy to a new equilibrium through influencing the structure of consumer and intermediate demand. The adjustment of relative prices is an instrument to mitigate the effect of restrictions, promoting both the reallocation of demand for other goods and the reallocation of supply to other production factors. Inoue and

\footnotetext{
${ }^{1}$ See the pages on pandemic-motivated research (including estimates of its economic impact) at VoxEU.org (https://voxeu.org/pages/covid-19-page) and NBER (https://www.nber.org/wp_covid19_09072020.html) as well as on the European Economic Association website (EEA, https://www.eeassoc.org/).

${ }^{2}$ A side-by-side comparison of studies examining the effects of the pandemic and industry-level restrictive measures was made by Pichler et al. (2020).

3 For example, in Pichler et al. (2020) 'industries that experience large direct output shocks do not reduce production much more in the course of the lockdown. In contrast, many industries that experience little or no direct shocks to their productive capacities downsize economic production substantially after two months'.
} 
Todo (2020) used an agent-based model of partial equilibrium on the granular data of inter-industry relationships of 1.6 million Japanese firms.

In our calculations, we used a partial equilibrium approach and methodology closest to that used by Pichler et al. (2020). Primary shocks are fed into the model and then propagated through the industries in an iterative procedure. Thus, it is possible to take into account not only the direct effects of a shock but also its feedback effects on the supply side. In addition, behavioural equations make it possible to take into account the influence of secondary effects on income, stocks, and, accordingly, aggregate demand. The results correspond to the situation in general equilibrium models when prices are sufficiently rigid (including relative prices). In this respect, our estimate of the effects of the pandemic is an upper estimate (the most pessimistic one).

An important point brings us closer to Pichler et al. (2020): we consider final demand shocks (internal/external) when analysing the effects of shock propagation among industries. As noted by Pichler et al. (2020), other studies based on industry data focus only on supply shocks (production closures) - that is, they model the effects on the demand side (through reduced income) as a consequence of restrictions on the supply side (inability to produce and sell). However, the official quarantine measures were not the only source of the constraints. Eichenbaum et al. (2020) indicate that even in the absence of quarantine measures self-imposed restrictions would increase consumers' propensity to save and change the consumption structure. Underestimation of these factors when modelling the sectoral effects of the pandemic can lead to errors in assessing the final effects of the pandemic and quarantine. Since what we feed into the model are not theoretical constraints on the ability to work but actually observed decreased demand volumes in various sectors of final demand, which incorporate both supply-side and demand-side effects, we deal with a more general specification of the primary shock.

Unlike Pichler et al. (2020), we do not set behavioural equations for the labour market (indicators of employment by industries); nor do we divide production factors into critical and non-critical when assessing the secondary effects of the pandemic on the output of industries through inter-industry relationships. We omit the intermediate phase with the labour market and immediately focus on the income of the employed. One of the reasons why Pichler et al. (2020) pay attention to labour market indicators is that the authors also model the effects of restrictions on the intensity of the pandemic itself (laid-off workers stay at home and do not contribute to the spread of infection). Taking into account characteristics of pandemic models, ${ }^{4}$ we abstract ourselves from such endogeneity of pandemic shock strength. As for the division of production factors into critical and noncritical for the industry's output (products of other industries), we consider this a rather subjective procedure at the level of aggregated industries. On the whole,

\footnotetext{
${ }^{4}$ See warnings against the use of epidemic models in the social sciences in Avery et al. (2020).
} 
our calculations do not take into account the effects influencing the intensity of the pandemic and do not separate non-critical production factors, thus further increasing our estimate of the output reduction.

2. We consider not only internal shocks (restrictions imposed within the country) but also the cumulative impact of reduced demand in the global economy on Russian exports.

When calibrating the export shock, we take into account the industry structure of Russia's participation in value added chains. In assessing the decline in output in trading partner countries, we consider their relationships through value added production chains. Bonadio et al. (2020) analysed the role of both internal and external shocks in the economy's response to the pandemic. The authors examined labour market restrictions and the propagation of their consequences in the industries of both the domestic economy and the economies of trading partner countries (the analysis was carried out for 64 countries on the basis of input-output tables). We did not model a decrease in demand for Russian exports as a result of quarantine restrictions in trading partner countries but considered a certain initial projected decrease in demand in partner countries, subsequently amplified by the feedback effects of a decrease in demand in their trading partner countries, as in the cited paper.

3. Unlike, for example, Gourinchas (2020) or Kozlowski et al. (2020), we focus on the short-term effects of the pandemic (over a one-year horizon) and do not investigate the long-term effects of the pandemic.

The short-term effects in our study are associated with quarantine restrictions and self-imposed restrictions of consumers during the pandemic, similar to many other papers cited above. However, our tools are flexible enough to simulate global events that may occur after the pandemic if some of primary shocks turn from temporary to permanent ones, for example, if the demand for certain types of services remains low even after the end of the pandemic.

4. Our paper is specific inasmuch as we deal with estimates for the Russian economy.

Among the estimates for 64 countries, the paper by Bonadio et al. (2020) contains information on the impact on Russia's GDP of shocks associated with restricted supply on the labour market in the domestic economy and trading partner countries. According to these estimates, Russia's GDP should decrease by $30 \%$ in total after the imposition of quarantine restrictions on the labour market, about 12 percentage points of which are due to the effect of restrictions on the labour market in trading partner countries. ${ }^{5}$

Bykau et al. (2020) analyse the impact of the pandemic on Russia's GDP using input-output tables. The authors predict a 5\% reduction in Russia's GDP due to a decrease in demand during the pandemic, including a downturn in global oil

${ }^{5}$ Sweden and Taiwan had the least significant GDP reduction, $21 \%$, and Vietnam had the highest, $40 \%$. 
prices, assuming that the part of export revenues not directly related to oil remains unchanged. Under the fiscal rule, the impact of oil prices on GDP may be limited. In contrast to Bykau et al. (2020), we consider a decrease in oil export volumes and a change in revenues from Russian exports in other industries as well. ${ }^{6}$ We also note that Bykau et al. (2020) use an expert assessment of primary internal shocks, while our estimates are based on data from industry financial flows.

Apart from the studies mentioned above, we are not aware of other applications of input-output tables to the analysis of the pandemic's consequences for the Russian economy.

5. We use current data on industry-level financial transactions from the Bank of Russia payment system.

During the acute phase of the pandemic (in April-May), the use of the Bank of Russia payment system's data on incoming financial flows across industries allowed to obtain estimates of the decline in business activity by industry and for the entire economy almost in real-time mode (on a weekly basis). It is due to such prompt estimates that we can interpret the reduction in financial flows as primary shocks as well as the subsequent change in output by industry and for the economy, as an effect produced by these shocks.

To our knowledge, we are the first to describe the use of industry-level cash flow data from national payment systems to assess the effects of the pandemic. Before the pandemic, Aprigliano et al. (2019) used similar data from the Bank of Italy payment system for nowcasting and GDP forecasting. However, their paper does not mention the availability of data on flow structure by industry.

For nowcasting of the magnitude of the shock for household demand (the largest component of GDP) and its subsequent effects during the pandemic, the existing studies actively use data on household banking transactions. For example, Andersen et al. (2020) used data from Denmark's largest bank on household expenditures by expenditure category. Baker et al. (2020) utilised user data from one of the American fintech platforms for similar purposes, and Carvalho et al. (2020) used data on 2.6 billion transactions of Spain's second largest bank. The Bank of England also uses bank card data to monitor consumer activity during the pandemic. $^{7}$

\section{Dynamic model based on an input-output model}

To assess the impact of the coronavirus pandemic on Russia's GDP, we used a simple model based on indicators of the input-output table of the Russian economy. It should be noted that the purpose of modelling is solely to project shocks observed

\footnotetext{
${ }^{6}$ It is likely that the authors did not aim to assess the effect of changes in oil revenues only since the paper was mainly devoted to the methodology for obtaining such calculations, and this exercise was given as an example.

${ }^{7}$ See https://www.bankofengland.co.uk/bank-overground/2020/how-are-we-monitoring-theeconomy-during-the-covid-19-pandemic
} 
in real time using the indicators of financial flows onto all industries of the economy. Assessment of the longer-term potential effects of the pandemic, which may be associated with a transformation in the industry and labour market structure, as well as changes in relative prices, are outside the scope of this study. Neither is the model aimed at evaluating the effects of monetary or fiscal policy.

An input-output model (input-output table) is a table showing a production and use structure for each product. In this way, for each product, the table indicates other products of other industries or imports used in the production of this product. In addition, it shows other industries or sectors (households, the public sector, non-residents/exporters) that use the product for further processing, investment, or final consumption. We use a simple iterative model to assess the secondary effects of primary internal and external shocks - namely, the effects induced by inter-industry interactions in the production and use of goods and services. This model determines the dynamics of output for 98 industries. In each period $t$ (corresponding to one week), the demand for goods produced by the industry $i$ is defined as

$$
Y_{i, t}=G_{i}+E_{i, t}+C_{i, t}+I_{i, t}+\sum_{j=1}^{j=98} A_{i, j, t},
$$

where $G_{i}$ is the consumption of goods $i$ by the sector of public administration and non-profit organisations serving households (this parameter is fixed throughout the entire simulation period), $E_{i, t}$ is the exogenously set dynamics of external demand for goods $i, A_{i, j, t}$ is the intermediate consumption of goods $i$ by industry $j, I_{i, t}$ is the use of goods $i$ for gross accumulation and $C_{i, t}$ is the use of goods $i$ for final consumption by households. $A_{i, j, t}, I_{i, t}, C_{i, t}$ are determined endogenously.

Final consumption of households in the next period depends on the dynamics of aggregate output with elasticity $\alpha$. In addition, household consumption is affected by exogenously specified shocks $\left(\theta_{t}\right)$ reflecting the impact of restrictive measures:

$$
C_{i, t+1}=C_{i, t}\left(1+\alpha\left(\frac{Y_{i, t}-Y_{i, t-1}}{Y_{i, t-1}}\right)\right)+\theta_{t}
$$

Thus, we obtain a new round of secondary effects that affect the output in the next period. We establish that $\alpha=0.25$. The fact that $\alpha$ is less than 1 reflects the assumption that (at least in the short term) not all of the decline in output will be transferred to the decline in wages, and not all of the decline in wages will be transferred to consumption. The parameter value was chosen heuristically; a test of the sensitivity of the results to this choice is given in Appendix 3.

The intermediate consumption of goods in other industries is also adjusted based on the current output. In the long term, the reduction in output is fully translated into a reduction in intermediate consumption; however, it occurs 
gradually (at different rates depending on the industry). ${ }^{8}$ This process is represented by industry coefficients $\delta_{i}$ ranging from 0.05 to 0.9 .

$$
A_{i, j, t+1}=A_{i, j, t}\left(1-\delta_{i}\left(\frac{A_{i, j, t}-A_{i, j}^{*}}{A_{i, j, t}}-\frac{Y_{i, t}-Y_{i}^{*}}{Y_{i, t}}\right)\right),
$$

where $A_{i, j}^{*}$ and $Y_{i}^{*}$ are the initial levels of intermediate consumption and output, respectively.

The dynamics of gross accumulation $(\beta=0.1)$ is determined in the same way:

$$
I_{i, t+1}=I_{i, t}\left(1-\beta\left(\frac{I_{i, t}-I_{i}^{*}}{I_{i, t}}-\frac{Y_{i, t}-Y_{i}^{*}}{Y_{i, t}}\right)\right) .
$$

We have to note that parametrisation of the model is not empirically justified. Nevertheless, such calculations help illustrate the mechanisms and temporal structure of the transmission of the impacts of restrictive measures and the decline in external demand. The tests on the sensitivity of results to the choice of parameters $\alpha$ and $\beta$ are given in Appendix 3. The choice of these parameters does not affect the simulation results.

\section{Primary and secondary shocks of restrictive measures}

We estimate the decline in GDP as a result of the impact of primary and secondary shocks for 2020Q2-2020Q4 (or 36 weeks starting from 1 April 2020; the starting date is determined based on the fact that non-working days in Russia started on 30 March). To simulate the impact of shocks on Russia's GDP (including global economy shocks), we divided the primary shocks associated with a reduction in final consumption into internal and external (or export) shocks.

When compiling a time profile of internal shocks (for 36 weeks), we proceed from Bank of Russia payment system data. For each industry, we calculated amounts of daily payments that companies with the corresponding Russian National Classifier of Economic Activities Code (OKVED) had as recipients (incoming payments). This figure is an indicator of revenue/demand in this industry. We assumed that the primary decline in demand for products in a given industry during the period of non-working days was equal to the average deviation from the normal level in the flow of incoming payments for that period in the relevant industry. ${ }^{9}$ For example, in April, the deviation of the average daily level of incoming payments for the services of temporary residences (hotels) was down 63\% from the normal level. This level of the primary shock to household consumption in the first weeks was included in our further calculations. The further time profile of primary shocks in domestic consumption (in the form of the deviation of consumption from the norm) was

\footnotetext{
8 This parameter was calibrated according to the asset turnover ratio (see Ponomarenko et al., 2018).

${ }^{9}$ See Monitoring of industry financial flows (https://www.cbr.ru/analytics/finflows/), section Methodological comments (in Russian).
} 
formed on the basis of our understanding of the role of a forced or voluntary reduction in demand under restrictive measures. Implementation of one of these two scenarios affects the speed of recovery after the removal of anti-coronavirus restrictions. In some industries, in the absence of other shocks, demand may quickly return to normal; in other industries (for example, tourism, restaurants, and hotels), restrictive measures may remain in effect, or consumers may voluntarily forego the goods and services of these industries due to changes in consumer preferences.

We estimated external primary shocks for Russia (reduction in Russian exports) on the basis of WIOD data, ${ }^{10}$ using the IMF outlook for the world's key economies (International Monetary Fund, 2020; the calculation procedure is described in detail in Appendix 2). The WIOD data enabled us to obtain an estimate of the full effect of the contraction of the global economy on Russian exports. We used this effect as a primary export shock for the Russian economy - that is, the shock from the reduced consumption of Russian goods by the rest of the world. The WIOD calculations used annual data. The time profile of shocks was calculated in proportion to the quarterly dynamics of global GDP in the IMF forecast with a recession bottom in 2020Q2 and a further decrease in the scale of the decline by the end of 2020.

It is important to note that for domestic consumption shocks, we consider only the deviation caused by the impact of restrictive measures to be the primary shock, and, for external shocks, the primary shock is the impact of the aggregate global decline in economic activity on the Russian economy. We did not specify the dynamics of primary shocks in the intermediate consumption of goods and services since one of the analysis objectives was to assess the impact of primary consumption shocks (internal and external) on the value added dynamics in other industries through inter-industry relationships and the intermediate consumption of their products.

\section{Results}

Our analysis led to several conclusions:

\section{Primary shocks introduced in a few industries propagate as secondary shocks to a much larger number of industries.}

In Figure 1, economic activity types in accordance with OKVED-200711 are indicated horizontally (in the columns), and the number of the week after the introduction of restrictive measures (the start of non-working days in Russia on 30 March 2020) is indicated vertically (in the rows). The colour indicates the scale of deviations in the output for this activity type from the normal level: the darker

\footnotetext{
${ }^{10}$ World Input-Output Database (WIOD) is an annual input-output model of the global economy; the data cover 56 sectors for 43 countries; see http://www.wiod.org/

${ }^{11}$ The Russian National Classifier of Economic Activities OK 029-2007. It served as the basis for the 2016 input-output model that we used for estimates. The numbers of economic activity types in the figure do not match the OKVED numbers; see the number correlation table in Appendix 4.
} 
Figure 1. Dynamics heatmap of the primary and secondary effects of the pandemic on output in the sectors of the Russian economy

\section{Economic activity types}
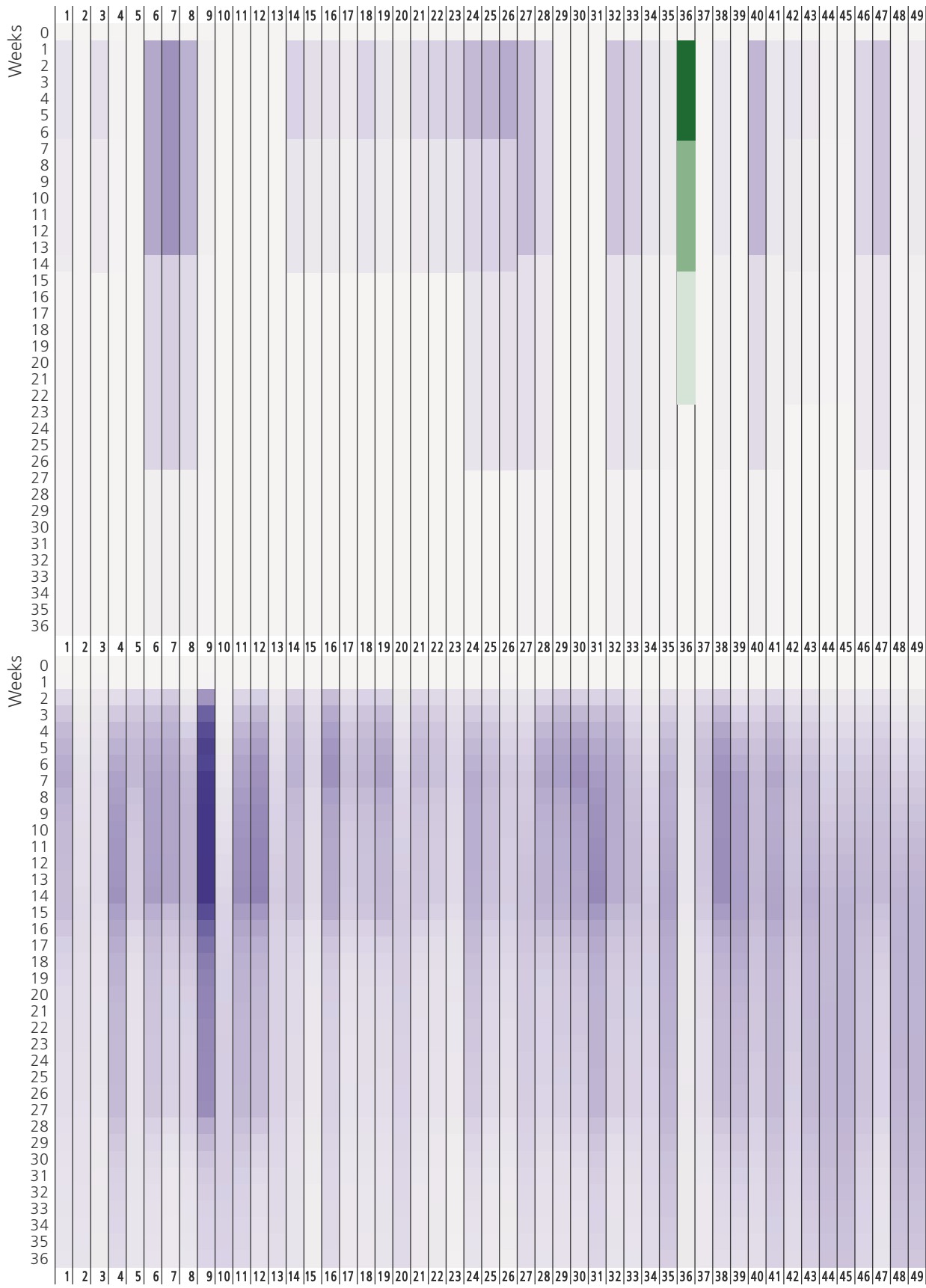
Figure 1. Continuation

\section{Economic activity types}

$|50| 51|52| 53|54| 55|56| 57|58| 59|60| 61|62| 63|64| 65|66| 67|68| 69|70| 71|72| 73|74| 75|76| 77|78| 79|80| 81|82| 83|84| 85|86| 87|88| 89|90| 91|92| 93|94| 95|96| 97|98|$

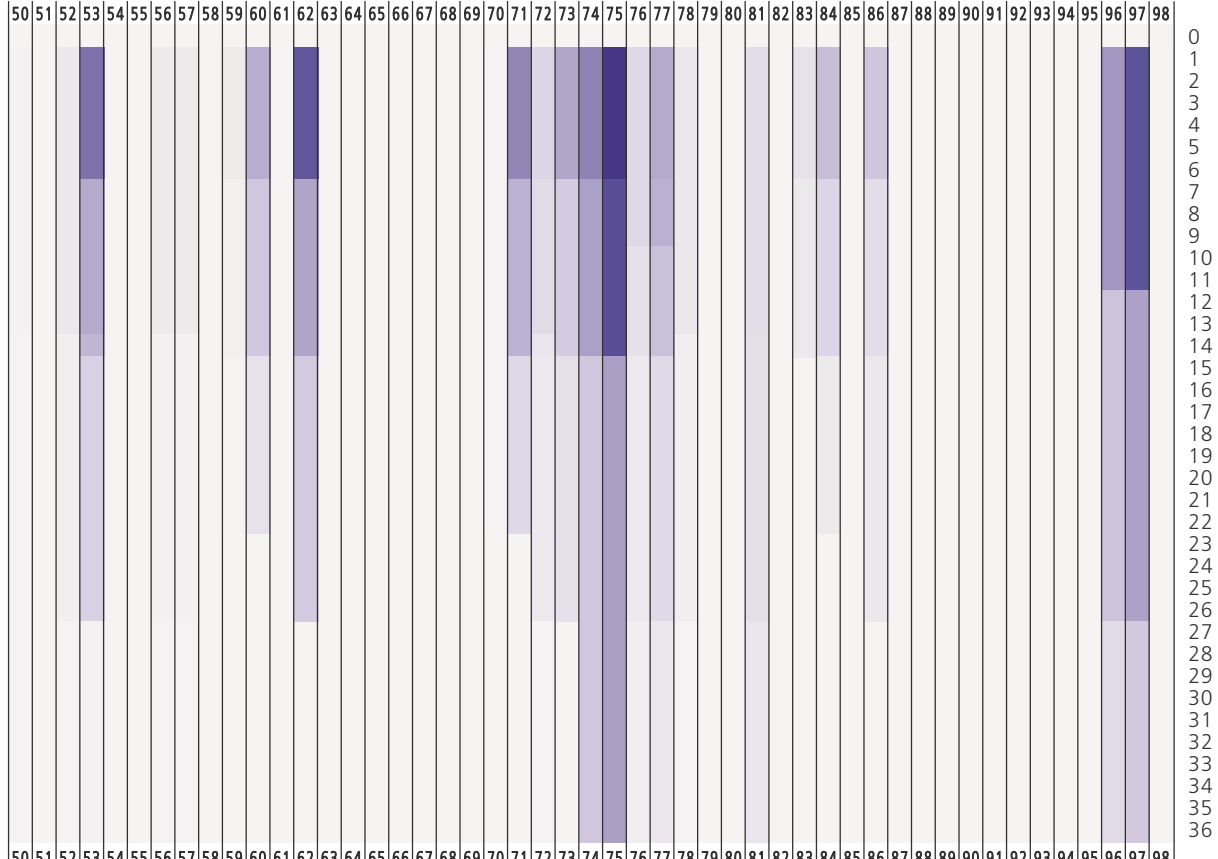

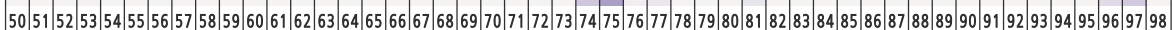

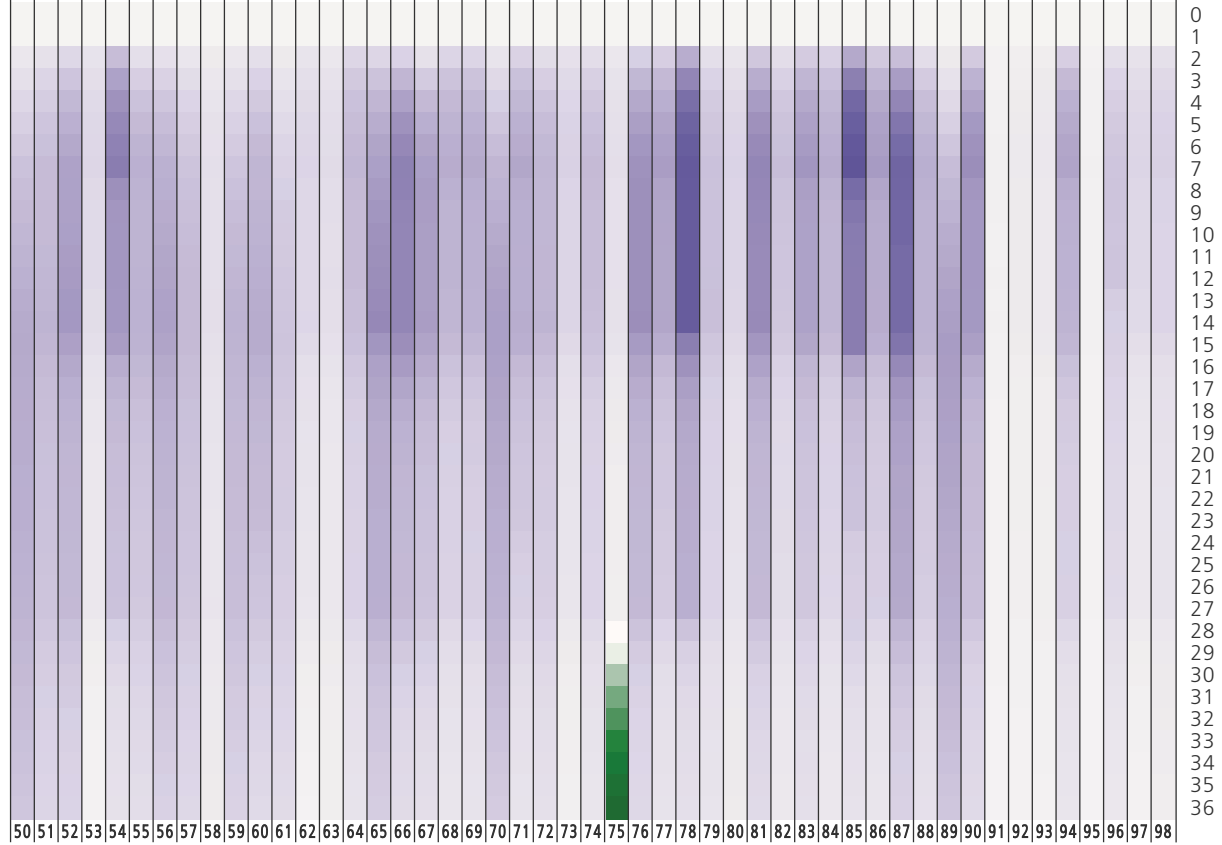


the area, the greater the deviation either downwards (violet ${ }^{12}$ ) or upwards $\left(\right.$ green $^{13}$ ). It should be noted the figure shows the total result of the impact of primary shocks in domestic consumption of households and in external consumption (export) on the output of the industry as a whole. The most affected industries were consumer services industries with activities partially or completely suspended during the non-working days period. Out of the export-oriented industries, the traditional export industries were affected the most: oil and gas extraction and oil refining. The only industry that experienced a positive primary shock (demand growth) was pharmaceutical manufacturing.

As seen in Figure 1, we set primary effects of the restrictive measures and the decrease in external demand for a relatively small number of industries. However, through inter-industry relationships, secondary effects affect output in a much larger number of industries.

\section{The secondary effects are larger in scale than the primary effects.}

Figure 1 shows that the scale of the secondary effects (deviation of output from the normal level) in many industries is greater than the scale of primary ones. This is supported by the assessments of the impact of secondary and primary shocks on the deviation of GDP (output) presented in Figure 2. During the first quarter of restrictive measures (2020Q2), the primary effect of the restrictions had the greatest impact on the decline in output. According to our estimates, the primary effects of the restrictive measures and the decline in external demand led to a decrease in output of about $4.7 \%$, and the secondary effects led to a decrease of an additional $3.7 \%$. As a result, output deviated from the pre-coronavirus trajectory by about 8.5\%. This is close to the estimated GDP decline in 2020Q2: 8\% YoY according to Rosstat's first estimate based on the production method and about 9\% QoQ (net of seasonal factors) according to the Bank of Russia estimate.

Figure 2. Impact of the primary and secondary shocks on deviation of GDP from the normal level (quarterly dynamics)

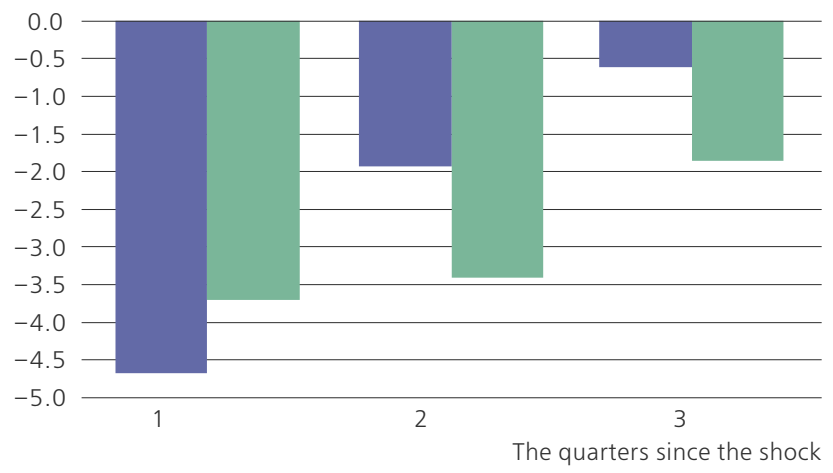

Sources: authors' estimates, Rosstat

\footnotetext{
${ }^{12}$ Lowest: $-43.4 \%$.

${ }^{13}$ Highest: $+13.3 \%$.
} 
As the restrictions are gradually lifted, the impact of the primary effects practically disappears by the end of the third quarter starting from the introduction of restrictive measures (in our case, 2020Q4). At the same time, the impact of the secondary effects weakens more slowly compared to that of the primary ones. In the second quarter of the restrictions, the deviation of GDP from the 'normal' level drops to $5.3 \%$ (1.9\% from the primary effects, $3.4 \%$ from the secondary effects) and, in the third quarter, to $2.5 \%$ ( $0.6 \%$ from the primary effects, $1.9 \%$ from the secondary effects). This indicates the validity of the assumption that the lifting of restrictive measures when the pandemic situation improves does not in itself lead to a rapid ( $\mathrm{V}$-shaped) recovery of economic activity.

3. The scale of the secondary effects relative to the size of the primary shock may vary widely across industries.

We calculated secondary effects from isolated primary shocks in selected industries. ${ }^{14}$ The results showed that the relative scale of shocks varies greatly. For example, for certain industries, secondary (taking into account the impact on the entire economy) effects are twice as large as the primary shock for this industry, for example, the chemical, metallurgical and food industries. For some industries, primary shocks create far fewer additional secondary effects: agriculture, oil and gas extraction and real estate transactions. The difference in the relative scales of shocks is due to the differing structure of intermediate consumption, the amount of value added by the industry and the length of production chains. This knowledge can be useful in developing programmes to support industries and to reduce the effect of restrictive measures on the economy. All other things being equal, targeted support can be provided not only to the industries creating the most value added but also to the industries that significantly affect the creation of value added via production chains in other industries.

\section{If the primary shocks do not disappear completely, potential output is lost.}

This will be true, for example, if certain restrictions remain in effect for a long time, as a result of which some of primary shocks may become permanent. It is quite possible that there occur structural changes on the demand side (changes in consumer preferences). This will lead to bankruptcies of many companies and loss of potential on the supply side. Moreover, secondary shocks generated by such primary shocks also become permanent. This also results in a loss of potential output to the extent that producers of intermediate and investment goods are not able to adapt production to the needs of other customers. Our assessment demonstrated that the influence of secondary effects on potential output loss turns out to be greater than the scale of primary shocks: in a hypothetical example of the permanent impact of primary shocks (see Figure 3), the impact of secondary shocks first manifests itself with a lag but ultimately turns out to be even stronger.

\footnotetext{
${ }^{14}$ For other industries, it was assumed there was no deviation from the 'normal' level.
} 
Figure 3. Impact of the primary and secondary shocks on deviation of GDP from the normal level

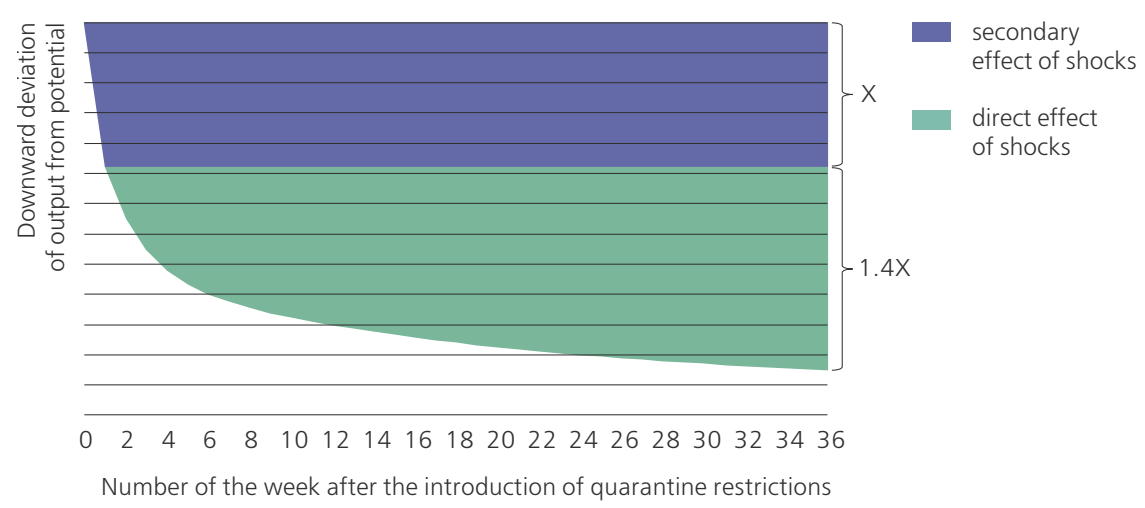

Sources: Rosstat, authors' estimates

\section{Conclusion}

In this paper, we have assessed the impact of both primary shocks to domestic consumer demand from restrictive anti-pandemic measures and to external demand for Russian exports from the global recession and the secondary effects induced by these shocks on Russia's GDP.

The impact of the restrictive measures and the decline in external demand lead to a decrease in intermediate and investment consumption and an additional decrease in final consumer demand due to lower wages in a wide range of industries subject to secondary effects.

As a result, the secondary effects turn out to be larger in scale than the primary ones. At the same time, the secondary effects are more persistent - that is, the reduction in their negative impact turns out to take much longer. This means that even after the restrictive measures are completely lifted, and external demand recovers, the recovery of the Russian economy will take time. Many central banks and international financial institutions base their current macroeconomic forecasts on this scenario of a slow and gradual recovery of the global economy after the coronavirus shock. In this situation, countercyclical fiscal and monetary policies can speed up economic recovery and mitigate the impact of secondary effects. However, it is important to take into account the fact that the impact of some of primary shocks may become permanent. This will lead to a decrease in the potential output of the economy, both directly through a decrease in final demand amid the impact of primary effects and through the secondary effects of shocks leading to a decrease in demand/production in related industries. 


\section{References}

Andersen, A. L., Hansen, E. T., Johannesen, N. and Sheridan, A. (2020). Consumer Responses to the COVID-19 Crisis: Evidence from Bank Account Transaction Data. CEPR Discussion Paper, N 14809.

Aprigliano, V., Ardizzi, G. and Monteforte, L. (2019). Using Payment System Data to Forecast Economic Activity. International Journal of Central Banking, 15(4), pp. 55-80.

Avery, C., Bossert, W., Clark, A., Ellison, G. and Ellison, S. F. (2020). Policy Implications of Models of the Spread of Coronavirus: Perspectives and Opportunities for Economists. NBER Working Paper, N 27007.

Baker, S., Farrokhnia, R. A., Meyer, S., Pagel, M. and Yannelis, C. (2020). How Does Household Spending Respond to an Epidemic? Consumption During the 2020 Covid-19 Pandemic. NBER Working Paper, N 26949.

Barrot, J. N., Grassi, B. and Sauvagnat, J. (2020). Sectoral Effects of Social Distancing. HEC Paris Research Paper, N 1371.

Bonadio, B., Huo, Z., Levchenko, A. A. and Pandalai-Nayar, N. (2020). Global Supply Chains in the Pandemic. CEPR Discussion Paper, N 14766.

Bykau, A., Parkhimenka, U. and Tolkachev, S. (2020). Influence of Covid-19 on the Russian Economy: Methodological Approaches to the Assessment Based on the Input-Output Tables. Belarusian Economic Journal, 2, pp. 25-37. [In Russian]. doi: 10.46782/1818-4510-2020-2-25-37

Carvalho, V. M., Garcia, J. R., Hansen, S., Ortiz, Á., Rodrigo, T., Rodríguez Mora, J.V. and Ruiz, P. (2020). Tracking the Covid-19 Crisis with High-Resolution Transaction Data. Cambridge Working Papers in Economics, N 2030.

Eichenbaum, M. S., Rebelo, S. and Trabandt, M. (2020). The Macroeconomics of Epidemics. NBER Working Paper, N 26882. doi: 10.3386/w26882

Gourinchas, P.-O. (2020). Flattening the Pandemic and Recession Curves. In: R. Baldwin and B. W. di Mauro, eds. Mitigating the COVID Economic Crisis: Act Fast and Do Whatever It Takes. A VoxEU.org Book. London: CEPR Press.

Inoue, H. and Todo, Y. (2020). The Propagation of the Economic Impact Through Supply Chains: The Case of a Mega-City Lockdown Against the Spread of Covid-19. PLOS ONE, 15(9), e0239251. doi: 10.1371/journal.pone.0239251

International Monetary Fund (2020). World Economic Outlook Update. A Crisis Like No Other, An Uncertain Recovery. Washington, DC, June.

Kozlowski, J., Veldkamp, L. and Venkateswaran, V. (2020). Scarring Body and Mind: The Long-Term Belief-Scarring Effects of COVID-19. NBER Working Paper, N 27439. doi: 10.3386/w27439

Pichler, A., Pangallo, M., del Rio-Chanona, R. M., Lafond, F. and Farmer, J. D. (2020). Production Networks and Epidemic Spreading: How to Restart the UK Economy? INET Oxford Working Paper, N 12.

Ponomarenko, A., Popova, S. and Sabodash S. (2018). Otraslevyye osobennosti dolgovogo finansirovaniya $v$ Rossii i uyazvimost' $k$ finansovym shokam [Sectoral Features of Debt Financing in Russia and Vulnerability to Financial Shocks]. Analytical Note of Bank of Russia Research and Forecasting Department, August. [In Russian]. Available at: http://www.cbr.ru/content/document/file/47472/analytic_note_180829_dip.pdf [accessed on 22 September 2020]. 